\title{
Major role for 5-alpha reductase inhibitors in the aging male
}

\author{
Neil Fleshner, MD, MPH
}

See related article on page 17

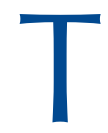

he Canadian consensus meeting, held in Toronto in May 2006, represents an important initiative in sorting out much of the confusion surrounding the use of 5-alpha reductase inhibitors (5ARIs) in clinical practice. The impact of the Medical Therapy of Prostatic Symptoms study and the Prostate Cancer Prevention Trial (PCPT) are quite dramatic as they confirm that 5ARIs, a class of drugs that never gained much market share in urologic practice, have significant impact on both benign prostatic hyperplasia (BPH) and prostate cancerrelated outcomes. It is quite ironic that these pivotal trials, funded not by industry but by tax payers, have come to fruition at a time when finasteride is soon to be genericized in the United States. Commercial interests aside, this consensus summary provides useful information for urologists and primary care physicians. With respect to BPH-related outcomes, the 5ARIs have clearly demonstrable benefits in reducing long-term complications and lower urinary tract symptoms (LUTS). There is little debate on this topic.

The impact of 5ARIs on prostate cancer prevention remains controversial and, in my mind, these recommendations have some limitations that deserve mention.

With respect to the grade and volume bias, this observation, internationally led by our group, is real, and many other centres are now reporting it. We must emphasize that these recommendations report that this bias explains the PCPT grade issue "with a high degree of confidence." While I truly believe this is the case, a small but lingering doubt must still exist within us all. It is essentially now unprovable! Perhaps more relevant than the grade issue is the clinical significance of the prevented cancers. Indeed, in the PCPT the relative risk reduction in "for-cause" biopsies, those that mirror clinical practice, is only $10 \%$. I believe that future pivotal trials, such as REDUCE (the Reduction by Dutasteride of Prostate Cancer Events study; dut- asteride $v$. placebo among men with negative prostate biopsy and elevated prostatespecific antigen), will help us clarify some of these issues.

With respect to class effect and use of 5ARIs, I believe that both 5ARIs are good agents and that there are theoretical advantages to dutasteride in cancer prevention. Further trials will bear this out.

What are clinicians to do?

- Consider the cancer prevention properties as an added benefit to complication reduction and symptom improvement for men with large-volume BPH and LUTS. In my view, either 5ARI is appropriate.

- Consider primary prevention with 5-ARI in ultra-high risk men, those in whom a cancer is likely to be clinically significant (e.g., men with strong family history, African-Canadians or both). In this setting, the best evidence would support the use of finasteride.

From the Division of Urology, Princess Margaret Hospital, University Health Network, Toronto, Ont.

Competing interests: None declared.

Correspondence: Dr. Neil Fleshner, Princess Margaret Hospital, 610 University Ave., Suite 3-130, Toronto ON M5G 2M9; Neil.Fleshner@uhn.on.ca 